\title{
Subclinical cardiovascular risk signs in adults with juvenile idiopathic arthritis in sustained remission
}

Inmaculada Concepción Aranda-Valera ${ }^{1 \dagger}$, Iván Arias de la Rosa ${ }^{1,2 \dagger}$, Rosa Roldán-Molina', María del Carmen Ábalos-Aguilera', Carmen Torres-Granados ${ }^{1}$, Alejandra Patiño-Trives ${ }^{1}$, María Luque-Tevar ${ }^{1}$, Alejandro Ibáñez-Costa ${ }^{1}$, Rocío Guzmán-Ruiz ${ }^{3}$, María del Mar Malagón ${ }^{3,4}$, Alejandro Escudero-Contreras ${ }^{1}$, Chary López-Pedrera ${ }^{1}$, Eduardo Collantes-Estévez ${ }^{1,2+}$ and Nuria Barbarroja ${ }^{1,2,4^{*} \dagger}$ (i)

\begin{abstract}
Background: Juvenile Idiopathic Arthritis (JIA) is one of the most common chronic diseases of childhood that often persists into adulthood and can result in significant long-term morbidity. As a long lasting chronic inflammatory disease, concern has been raised regarding the risk of premature development of cardiovascular disease (CVD) in JIA. This study aims to determine whether adults with JIA in clinical remission display clinical and subclinical signs of CVD risk: inflammatory mediators, adipokines, endothelial dysfunction and oxidative stress markers.

Methods: This is a cross-sectional study including 25 patients diagnosed with JIA according to the International League of Associations for Rheumatology criteria (ILAR 2001) and 25 age- and sex-matched controls. Remission was determined by JADAS10 < 1 and according to Wallace criteria. The presence of traditional CVD risk factors was analyzed. An extensive clinical analysis including body mass index (BMI), lipid profile, homeostatic model assessment insulin resistance (HOMA-IR) and arterial blood pressure was performed. Intima media thickness of the common carotid artery (CIMT) was measured as a marker of subclinical atherosclerosis. Several proinflammatory cytokines, molecules involved in the endothelial dysfunction, oxidative stress and adipokines were quantified on serum by ELISA and on peripheral blood mononuclear cells (PBMCs) by RT-PCR. In vitro studies were carried out in healthy PBMCs, adipocytes and endothelial cells which were treated with serum from JIA patients under sustained remission.

(Continued on next page)
\end{abstract}

\footnotetext{
* Correspondence: barbarrojan@gmail.com

${ }^{\dagger}$ Inmaculada Concepción Aranda-Valera and Iván Arias de la Rosa share the

first authorship and contributed equally.

'Eduardo Collantes-Estévez and Nuria Barbarroja share the senior authorship

${ }^{1}$ Rheumatology Department, IMIBIC/Reina Sofía University Hospital/University of Cordoba, Cordoba, Spain

${ }^{2}$ Medicine Department, University of Cordoba/IMIBIC/Reina Sofía University Hospital, Cordoba, Spain

Full list of author information is available at the end of the article
}

(c) The Author(s). 2020 Open Access This article is licensed under a Creative Commons Attribution 4.0 International License, which permits use, sharing, adaptation, distribution and reproduction in any medium or format, as long as you give appropriate credit to the original author(s) and the source, provide a link to the Creative Commons licence, and indicate if changes were made. The images or other third party material in this article are included in the article's Creative Commons licence, unless indicated otherwise in a credit line to the material. If material is not included in the article's Creative Commons licence and your intended use is not permitted by statutory regulation or exceeds the permitted use, you will need to obtain permission directly from the copyright holder. To view a copy of this licence, visit http://creativecommons.org/licenses/by/4.0/. The Creative Commons Public Domain Dedication waiver (http://creativecommons.org/publicdomain/zero/1.0/) applies to the data made available in this article, unless otherwise stated in a credit line to the data. 
(Continued from previous page)

Results: Mean duration of the disease was $13.47 \pm 5.47$ years. Mean age was $25.11 \pm 7.21$. Time in remission was $3.52 \pm$ 3.33 years. Patients were in remission with no treatment (40\%) and with treatments (60\%). CVD risk factors and CIMT were similar in JIA patients and controls. However, cholesterol levels were significantly elevated in JIA patients. Levels of adipocytokines, oxidative stress and endothelial activation markers were elevated in serum and PBMCs from JIA patients. Serum of those JIA patients induced the activation of adipocytes, endothelial cells and healthy PBMCs.

Conclusions: JIA adult patients in remission have subclinical signs of inflammation and CVD risk, showed by an increase in the levels of inflammatory cytokines, endothelial activation and oxidative stress markers and adipokines, molecules closely involved in the alteration of the vascular system.

Keywords: Juvenile idiopathic arthritis, Cardiovascular risk, Clinical remission

\section{Background}

Juvenile idiopathic arthritis (JIA) is the most common chronic inflammatory arthritis in children and young people, with onset under the age of 16 years and being characterized by long standing pain, swelling and stiffness in joints $[1,2]$. In the pathogenesis and progression of JIA, the unbalance between pro- and anti- inflammatory cytokines might be involved in the regulation of systemic inflammation, local joints damage and bone erosion [3]. In recent decades, there has been considerable interest in the long-term outcomes of individuals with chronic inflammatory arthritis and an area of particular concern has been the increased prevalence of cardiovascular disease (CVD). This increased risk is attributed to a higher prevalence of traditional CVD risk factors and the role of systemic inflammation in the acceleration of atherosclerosis. In fact, increased cardiovascular mortality and morbidity have been observed in Rheumatoid arthritis (RA) patients [4].

Previous studies found increased traditional CVD risk factors in JIA, including family history of CVD, hypertension, and even smoking habit [5]. Additionally, an alteration of the lipid profile has been observed. Although that data could be controversial, most of the studies agree with the elevation of the levels of low density lipoproteins (LDL) and triglycerides and the decrease of high density lipoproteins (HDL) levels [5]. One of the best validated methods to evaluate CVD risk is the pathological increase in the intima media thickness (CIMT), which predicts the early atherogenesis and thus the occurrence of future cardiovascular events in the general population [6]. Hence, in other autoinflammatory diseases such as RA, the pathological increase in CIMT has been related to the enhanced risk of suffering cardiovascular events [7-9].

The chronic inflammation is also a well-defined nontraditional CVD risk in the pathogenesis of atherosclerosis [10], where cytokines including IL-1, IL-6 and TNF$\alpha$ could promote endothelial dysfunction, a key process in atherogenesis $[11,12]$. Few studies have evaluated the CIMT in JIA patients showing controversial data [13-
15]. The most recent results point out to an increase in CIMT of these patients, correlating with endothelial dysfunction parameters [16].

Others subclinical CVD risk signs have been identified in the general population. Among them, in JIA, circulating levels of intercellular adhesion molecule (ICAM) and E-selectin are elevated [17]. On the other hand, adipokines, cytokines released mainly by the adipose tissue, are key factors in the metabolic comorbidities that increase the CVD risk. Not only contribute to the regulation of process mediated by insulin, glucose and lipid metabolism, vascular changes and coagulation, but also participate in the chronic inflammatory state. Thus, in severe JIA, levels of leptin are elevated regardless the fat mass [18]. However, to date, few studies have evaluated the role of adipokines in the pathogenesis of JIA.

Diverse studies have suggested that JIA is associated with an increased CVD risk, due to a higher prevalence of traditional CVD risk factors and the cumulative damage from chronic inflammation. Most of these works have been carried out in patients with acute phase. Beyond to an active state, it is unknown whether inflammatory mediators, molecules released by adipose tissue and endothelial dysfunction markers could be present in JIA in sustained remission, contributing to the cardiovascular risk associated with this disease.

Our study provides new evidences about subclinical cardiovascular risk signs that could be present in patients with a remission state of the disease, which could alert the clinical specialist about the need for a tighter control of the disease.

\section{Methods \\ Patients}

Twenty-five JIA patients and twenty-five healthy donors (HDs) age-sex-matched with no history of autoimmune disease were included in this cross-sectional study. The participants were Caucasian and recruited at Rheumatology Department (pediatric unit), Reina Sofia University Hospital, Cordoba, Spain, after approval from the ethics committee and signed the informed consent. 
The recruitment participant's diagnoses were made according to the International League of Associations for Rheumatology (ILAR) criteria [19]. Disease activity was assessed using the Juvenile Arthritis Disease Activity Score-10 (JADAS-10), C reactive protein (CRP) [20] considering states of inactive disease, cutoff values $\leq 1$ [21]. Remission state was determined according to Wallace criteria [22]. Regarding treatment regimen, $40 \%$ out of patients were in remission with no treatment $(n=10)$ and $60 \%$ were under treatments $(n=15)$ (Table 1$)$. Four patients were on minimal doses of prednisone as maintenance treatment (maximum $5 \mathrm{mg} /$ day) at the time of the recruitment.

Peripheral blood samples were collected from patients and HDs following fasting for $8 \mathrm{~h}$ for laboratory tests. Tests were performed in all patients to determine the presence of anti-citrullinated protein antibodies (ACPAs) and rheumatoid factor (RF). Besides, metabolic profile such as, glucose, insulin, hemoglobin $1 \mathrm{Ac}$, total cholesterol (TC), HDLcholesterol, LDL-cholesterol, triglycerides (TGs), apolipoprotein A (ApoA), apolipoprotein B (ApoB), acute phase reactants such as CRP and erythrocyte sedimentation rate (ESR) and complement factors as complement component 3 (C3) and component 4 (C4) were recorded (Table 1). Additionally, the presence of traditional cardiovascular risk factors including smoking, obesity based on body mass index $(\mathrm{BMI}>30 \mathrm{Kg} / \mathrm{m} 2)$, type 2 diabetes mellitus (T2DM) (fasting blood glucose levels $>126 \mathrm{mg} / \mathrm{dL}$, hemoglobin A1c level $>6.5 \%$ or antidiabetic treatment) and hypertension were analyzed. Likewise, the prevalence of Metabolic Syndrome (MetSyn) was evaluated according to the National Cholesterol Education Program (NCEP) adult treatment panel III (ATP III) criteria, where 3 of the 5 following characteristics are met: abdominal obesity (male (>102 cm); female $(>88 \mathrm{~cm}), \mathrm{TG}>150 \mathrm{mg} / \mathrm{dL}$, HDL cholesterol (male $(<40 \mathrm{mg} / \mathrm{dL})$; female $(<50 \mathrm{mg} / \mathrm{dL})$; blood pressure $>130$ / $85 \mathrm{mmHg}$; fasting glucose $>110 \mathrm{mg} / \mathrm{dL})$.

\section{Carotid intima media thickness}

All subjects underwent high-resolution B-mode ultrasonography for carotid intima media thickness (CIMT) measurements. All ultrasound scanning was performed by a single experienced vascular sonographer on the left and right common carotid arteries, using carotid duplex equipment (LOGIC E9). IMT was measured at the distal wall of the carotid artery on a 10-mm segment and defined as the distance from the leading edge of the lumen-intima surface to the leading edge of the mediaadventitia interface of the far wall.

\section{Atherogenic risk}

Atherogenic risk was calculated by atherogenic index (AI) based on the levels of TC (mg/dL) and HDL (mg/
$\mathrm{dL}): \mathrm{AI}=\mathrm{TC} / \mathrm{HDL}$. Risk was delimited as $>4.5$ in female and $>5$ in male [23].

\section{Apolipoprotein $\mathrm{B} / \mathrm{A}$ risk}

Apolipoproteins ratio was used to establish CVD risk due to the levels of apolipoproteins A and B. Relative CVD risk groups were: low CVD risk (female: 0.30-0.59; male: $0.40-0.69$ ), moderate CVD risk (female: 0.60-0.79; male: $0.70-0.89$ ) and high CVD risk (female: 0.8-1.0; male: $0.9-1.1$ ). In this study, to calculate the prevalence of CVD risk by ApoB/ApoA ratio, subjects were separated in two groups: low CVD risk and moderate-high CVD risk [24, 25].

\section{SCORE CVD risk}

SCORE model was used to determined CVD risk based on traditional CV risk factors such as sex, age, systolic pressure, smoking, TC and HDL-cholesterol following EULAR recommendations for CVD risk [26].

\section{Insulin resistance}

The homeostatic model assessment-insulin resistance (HOMA-IR) index was used to measure IR: [insulin concentration $(\mathrm{mU} / \mathrm{L}) \mathrm{x}$ glucose concentration $(\mathrm{mg} / \mathrm{dL})] /$ 405 (HOMA-IR values $>2.5$ indicated IR) [27].

\section{Serum levels of adipokines, cytokines and adhesion molecules}

Serum levels of tumor necrosis factor-alpha (TNF- $\alpha$ ), interleukin 1-beta (IL-1 $\beta$ ), interleukin 6 (IL-6), intercellular adhesion molecule (ICAM-1), E-selectin and vascular endothelial growth factor A (VEGF-A) were quantified by enzyme-linked immunosorbent assay, following the manufacturer's instructions (Bionova, Diaclone, Madrid, Spain). Serum levels of leptin, adiponectin (adipoQ), resistin (Bionova, Cusabio, Madrid, Spain) and visfatin (RayBiotech, Norcross, GA (EEUU)) were determined by ELISA following the manufacturer's instructions.

\section{Peripheral blood mononuclear cells (PBMCs)}

PBMCs were isolated from JIA patients and HDs through Ficoll density gradient. Total RNA was extracted from PBMCs by using a RNA purification kit following the manufacturer's instructions (Norgen Biotek Corp., ON, Canada). The RNA purity was verified by optical density (OD) absorption ratio OD260/OD280 between 1.8 and 2.0.

\section{In vitro studies}

Mechanistic studies were performed with PBMCs isolated from HDs and cell lines: human umbilical vein endothelial cells (HUVEC) and 3 T3-L1 adipocytes (murine).

Isolated PBMCs from HDs were cultured in medium [RPMI 1640 containing $2 \mathrm{mM} \mathrm{L-glutamine,} 100 \mathrm{U} / \mathrm{mL}$ 
Table 1 Clinical details of JIA patients and healthy donors

\begin{tabular}{lll}
\hline Clinical parameters & $\begin{array}{l}\text { Healthy donors } \\
\boldsymbol{n}=25\end{array}$ & $\begin{array}{l}\text { JA patients } \\
\boldsymbol{n}=25\end{array}$ \\
\hline Female/Male $(\mathrm{n} / \mathrm{n})$ & $13 / 12$ & $14 / 11$ \\
Age (years) & $27.21 \pm 2.54$ & $25.11 \pm 7.21$ \\
Disease duration (years) & - & $13.47 \pm 5.47$ \\
Remission duration (years) & - & $3.52 \pm 3.33$ \\
RF $+(\mathrm{n})$ & 0 & 1 \\
ACPAs $+(\mathrm{n})$ & 0 & 1 \\
CRP $(\mathrm{mg} / \mathrm{dl})$ & $0.95 \pm 1.19$ & $2.88 \pm 5.54$ \\
ESR $(\mathrm{mm} / \mathrm{h})$ & $6.53 \pm 3.82$ & $5.47 \pm 3.54$ \\
C3 $(\mathrm{mg} / \mathrm{dL})$ & $124.15 \pm 12.51$ & $124.16 \pm 16.03$ \\
C4 $(\mathrm{mg} / \mathrm{dL})$ & $20.84 \pm 4.01$ & $25.97 \pm 7.19$
\end{tabular}

\section{JIA subtypes}

Systemic (\%)

Oligoarthritis (\%)

RF-negative polyarthritis (\%)

RF-positive polyarthritis (\%)

Psoriatic (\%)

Enthesitis-related arthritis (\%)

Undifferentiated (\%)

\section{Metabolic profile}

BMI

Glucose (mg/dl)

Insulin (mU/L)

$\mathrm{HbA1c}(\%)$

Total Cholesterol (mg/dl)

HDL-Cholesterol ( $\mathrm{mg} / \mathrm{dl})$

LDL-Cholesterol (mg/dl)

Triglycerides (mg/dl)

ApoA (mg/dl)

ApoB (mg/dl)

\section{Treatments}

No treatment (n)

Corticosteroids ( $n$ )

Salazopyrin (n)

NSAIDS (n)

Methotrexate (n)

Anti-TNF-a (n)

$\begin{array}{ll}- & 24 \\ - & 20 \\ - & 4 \\ - & 24 \\ - & 24 \\ - & 0\end{array}$

$$
\begin{aligned}
& 22.49 \pm 3.13 \\
& 83.64 \pm 6.38 \\
& 7.10 \pm 3.52 \\
& 5.12 \pm 0.11 \\
& 163.57 \pm 24.75 \\
& 52.21 \pm 10.23 \\
& 95.50 \pm 21.46 \\
& 75.35 \pm 33.87 \\
& 136.35 \pm 25.50 \\
& 69.64 \pm 15.63
\end{aligned}
$$$$
22.70 \pm 4.32
$$

\section{4}

24

20

4

24

24

0

$76.47 \pm 11.20$

$5.79 \pm 2.76$

$5.15 \pm 0.30$

$180.26 \pm 29.92$

0.046

$57.63 \pm 15.22$

$105.00 \pm 29.17$

$83.31 \pm 50.58$

$140.77 \pm 24.16$

$77.11 \pm 18.36$

10

4

2

3

2

4

Values are means $\pm S D$, unless otherwise stated

JIA, juvenile idiopathic arthritis; RF, rheumatoid factor; ACPAs, antibodies to citrullinated protein antigens; JADAS: juvenile idiopathic arthritis disease activity score; $\mathrm{CRP}, \mathrm{C}$-reactive protein; ESR, erythrocyte sedimentation rate; $\mathrm{C} 3$, complement component 3; C4, complement component 4; BMI, body mass index, HbA1C, hemoglobin A1c; HDL, high density lipoprotein; LDL, low density lipoprotein; ApoA, apolipoprotein A; ApoB, apolipoprotein B; NSAIDS, non-esteroidal antiinflammatory drugs; TNF-a, tumor necrosis factor alpha

penicillin, $100 \mathrm{mg} / \mathrm{mL}$ streptomycin and $250 \mathrm{pg} / \mathrm{mL}$ fungizone (BioWhittaker/MA Bioproducts, Walkersville, MD, USA) at $37^{\circ} \mathrm{C}$ in a humidified $5 \%$ carbon dioxide $(\mathrm{CO} 2)$ ] atmosphere and treated with $10 \%$ of inactivated serum (incubated at $56 \%$ for 30 mins) from JIA patients and HDs for $24 \mathrm{~h}$. Cells were collected for RNA isolation and applied to RT-PCR analysis. 
HUVEC cells were purchased from ATCC (Manasas, VA, USA). Cells were cultured in Endothelial Cell Basal medium (EBM; Lonza, Walkersville, Md) with 10\% FBS, $0.1 \%$ human epidermal growth factor (hEGF), $0.1 \%$ hydrocortisone, $0.1 \%$ gentamicin, amphotericin-B (GA1000), $0.4 \%$ bovine brain extract, $100 \mathrm{U} / \mathrm{mL}$ penicillin, $100 \mathrm{mg} / \mathrm{mL}$ streptomycin, and $250 \mathrm{pg} / \mathrm{mL}$ fungizone (BioWhittaker/MA Bioproducts, Walkesvile, Md) at $37{ }^{\circ} \mathrm{C}$ in a humified $5 \% \mathrm{CO} 2$ atmosphere. For in vitro experiments, HUVECs were seeded into 6 -well plates $(4 \times$ $10^{5}$ cells per well) in $1.5 \mathrm{~mL}$ of completed medium. After $24 \mathrm{~h}$, cells were treated with $10 \%$ of inactivated serum from JIA patients and HDs for $24 \mathrm{~h}$. Subsequently, cells were collected for mRNA analyses.

3 T3-L1 cells were purchased from ATCC (Manasas, VA, USA). Cells were cultured and differentiated into adipocytes according to the protocol described previously [28]. Differentiated cells were used when at least $90 \%$ showed an adipocyte phenotype by accumulation of lipid droplets by day 8 . On day 8 of differentiation, cells were treated with medium containing $10 \%$ of inactivated JIA or HDs serum for $24 \mathrm{~h}$. Cells were harvested for total RNA isolation and applied to gene expression studies.

\section{Gene expression analysis}

The expression of genes involved in inflammation (TNF$\alpha$, IL-1 $\beta$ IL-6, IL-8, interferon (IFN) $-\gamma$ monocyte chemoattractant protein-1 (MCP-1), toll like receptor (TLR)-2 and TLR-4), oxidative stress (superoxide dismutase (SOD)-1, SOD-2, inducible nitric oxide synthase (iNOS), endothelial nitric oxide synthase (eNOS) and glutathione peroxidase (GPX)-1, endothelial dysfunction (VEGF-A, ICAM-1, vascular cell adhesion molecule (VCAM)-1 and E-selectin) and adipokines (leptin, adiponectin, visfatin and resistin) was analyzed in PBMCs, endothelial cells and adipocytes through RT-PCR.

Real-time PCR using SYBR green was performed according to the manufacturer's instructions (Thermo Fisher Scientific, Madrid, Spain). Expression of genes of interest was corrected by the geometrical average of $\beta$ actin, glyceraldehyde-3-phosphate dehydrogenase and hypoxanthine-guanine phosphoribosyltransferase using the BestKeeper tool [29].

\section{Statistical analysis}

Statistical analysis and graphs were performed by GraphPad Prism 8.0.1. Descriptive data are presented as the mean and standard deviation (SD) for continuous variables and as absolute frequencies and percentages for categorical ones. Kolmogorov-Smirnov test for normal distribution was carried out. To compare two independent groups (HDs vs JIA patients, JIA patients with treatments vs JIA patients with no treatment, cells treated with HD serum vs cells treated with JIA serum), following normality and equal variance tests, Student's ttest or alternatively a non-parametric test (Mann-Whitney rank sum test) were used. Qualitative data was analyze using Chi-squared test (presence of cardiovascular risk factors). Correlations among the levels of serum adipocytokines, lipid profile and clinical parameters were assessed by Spearman's rank correlation. $p<0.05$ was considered statistically significant.

Multiple testing correction with fold discovery rate approach was carried out in all the in vivo measures. In these cases, statistical significance was considered when $p$ value $<0.05$ and $\mathrm{FDR}<0.1$.

\section{Results}

Clinical inflammatory markers and cardiovascular risk factors in JIA patients in remission

In our cohort of JIA patients, mean age was $25.11 \pm 7.21$ years old, with a mean duration of the disease of $13.47 \pm$ 5.47 years. Most of them were in clinical remission for more than 2 years, with mean remission time of $3.52 \pm$ 3.33 years. Regarding lipid profile, total cholesterol levels were significantly increased in JIA patients compared to healthy donors. Of note, although these patients were in remission, levels $\mathrm{C} 4$ were significantly elevated (Table 1 ).

Traditional CVD risk factors such as smoking and metabolic syndrome were elevated in JIA compared to age-gender matched HDs. Increased ApoB/ApoA and atherogenic risks were also increased in JIA patients, although there were no statistically differences in all these parameters (Fig. 1a). Regarding insulin resistance and BMI, no changes in the rates between patients and healthy donors were noticed (Fig. 1a and Table 1).

SCORE was similar in JIA patients and HDs (Fig. 1b). Likewise, there was no significant difference in the levels of CIMT between JIA patients and HDs $(0.44 \pm 0.009$ vs $0.41 \pm 0.017, p=0.078$ ) (Fig. 1c).

\section{Serum levels of adipocytokines and endothelial adhesion molecules in JIA patients in remission}

Although these patients were in remission, serum levels of inflammatory cytokines including TNF- $\alpha$, IL- 6 and IL-1 $\beta$ were significant elevated compared to HDs (Fig. 2a-c). Of note, serum levels of adipokines were altered in JIA patients, showed by a significant increase in visfatin and resistin levels, suggesting an alteration in adipose tissue related to JIA (Fig. 2d-g). These results suggest that the longstanding inflammation, even under remission conditions, might promote alterations in the adipose tissue of these patients, increasing the risk of cardiovascular disease. Likewise, levels of molecules closely involved in endothelial dysfunction were elevated in JIA patients with a significant augmentation of VEGF$\mathrm{A}$, indicating an activation of the vascular endothelium (Fig. 2h-j). 


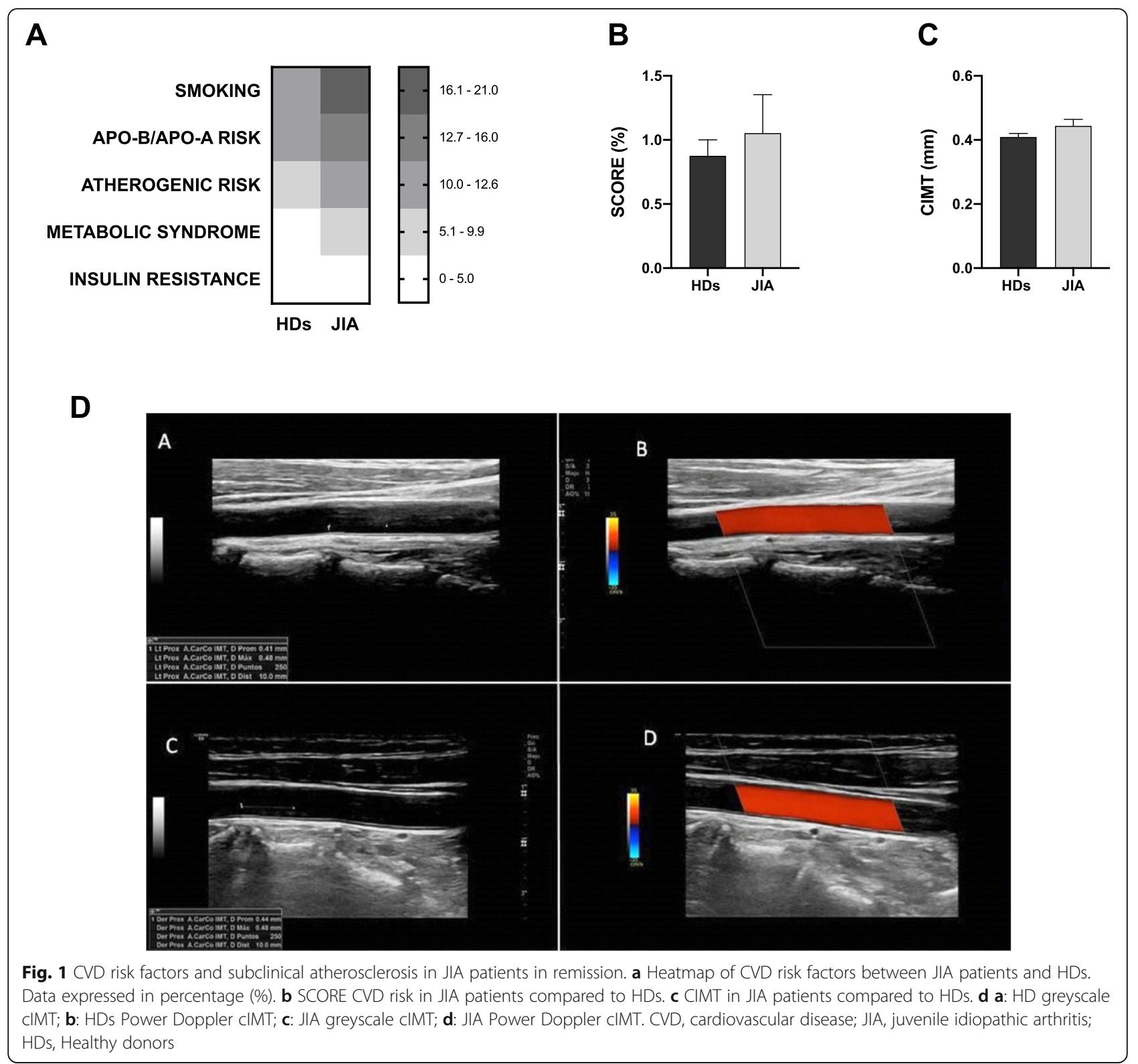

In addition, levels of all those molecules correlated with clinical parameters. Thus, levels of inflammatory cytokines (IL-1 $\beta$, TNF- $\alpha$ and IL-6) significantly correlated with clinical inflammatory markers such as $\mathrm{C} 4$ and with the duration of the disease, independently on the remission state (Fig. 2k). On the other hand, increased levels of adipokines such as visfatin significantly correlated with altered levels of $A p o B$ and ApoA, suggesting its contribution to lipid metabolism. In addition, augmented resistin levels were in line with the increase in the TNF- $\alpha$, indicating the relationship between inflammation and adipose tissue dysfunction in JIA patients (Fig. 2k).

Moreover, peripheral mononuclear cells of JIA patients (monocytes and lymphocytes) had increased expression of inflammatory mediators, such as TNF- $\alpha$, IL-8, MCP-1 and TLR-2 (Fig. 3a), and oxidative stress markers including SOD-1 and eNOS (Fig. 3b).

Since $60 \%$ out of the JIA patients were under treatments, we analyzed whether those treatments could interfere in all the parameters studied. No statistical differences were observed in the prevalence of CV risk factors and the levels of inflammatory mediators, adipokines and endothelial dysfunction and oxidative stress markers between patients in remission with no treatments and with any treatment.

JIA serum induces alterations in peripheral mononuclear and endothelial cells and adipocytes

The effect of serum from those JIA patients in remission, which has been shown to have high levels of 
A

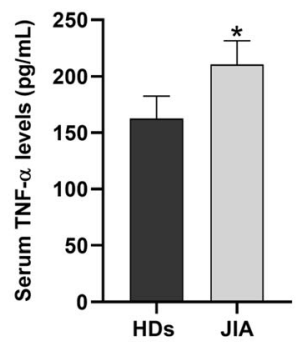

B

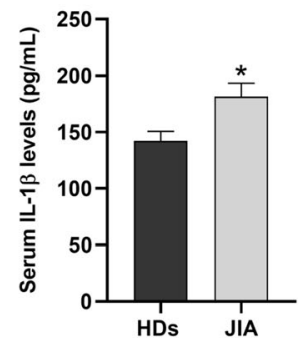

C

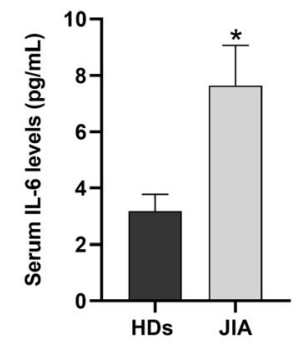

D

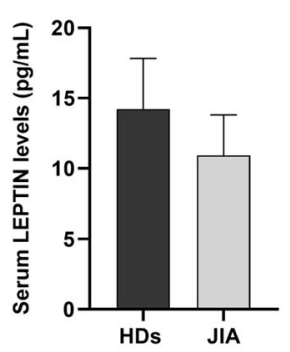

H

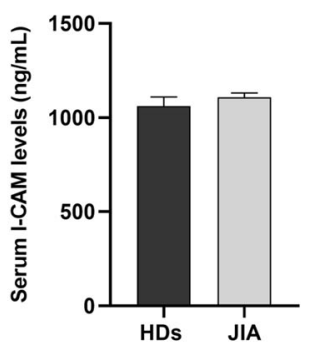

E

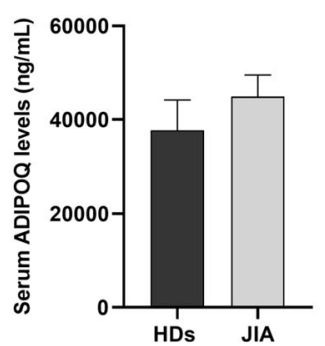

$\mathbf{F}$

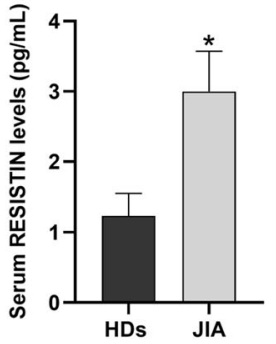

G

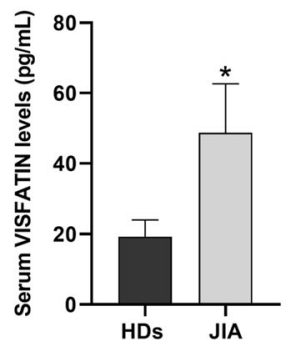

\section{I}

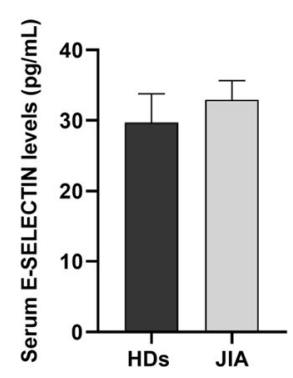

J

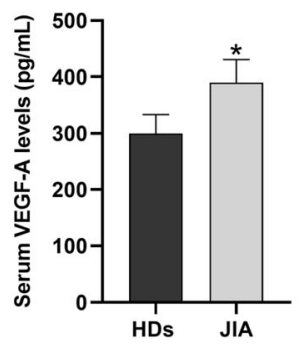

K

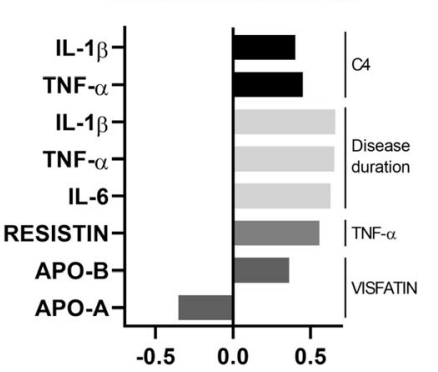

Fig. 2 Adipocytokines and endothelial adhesion molecules in serum of JIA patients in remission compared to HDs. a Serum TNF-a levels. $\mathbf{b}$ Serum IL-1 $\beta$ levels. c Serum IL-6 levels. d Serum Leptin levels. e Serum AdipoQ levels. f Serum Resistin levels. $\mathbf{g}$ Serum Visfatin levels. $\mathbf{h}$ Serum ICAM-1 levels. i Serum E-Selectin levels. j Serum VEGF-A levels. k Correlation coefficients of circulating molecules and clinical parameters. TNF-a: tumor necrosis factor-alpha; IL-1ß: interleukin-1 $\beta$; IL-6: interleukin-6; AdipoQ: adiponectin; VEGF-a: vascular endothelial growth factor-A; C4: complement component 4; ApoB: apolipoprotein b; ApoA: apolipoprotein A. ${ }^{*}$ Significant differences vs. HDs serum ( $p$ value<0.05 and FDR < 0.1)

inflammatory mediators, on healthy cells was analyzed. The treatment of peripheral mononuclear cells isolated from healthy donors with serum from JIA patients in remission promoted an increase in the levels of inflammatory mediators (TNF- $\alpha$, IL- $1 \beta$, IL-6, IL- 8 and IFN- $\gamma$ ), oxidative stress markers (SOD-1 and SOD-2) and adipokines (visfatin and resistin) compared to the treatment with serum from healthy donors (Fig. 4a-c).

In endothelial cells, the treatment with JIA serum induced the mRNA expression of VEGF-A and E-selectin, and inflammatory mediators such as IL-8 and TLR-4, suggesting that this serum is able to activate the endothelial cells (Fig. 4d-f).
As altered levels of adipokines on the serum of JIA patients was observed, we evaluated the direct effect of the JIA serum in the adipocytes. Thus, the treatment of these cells with serum of JIA patients induced the expression of inflammatory cytokines and chemokines, and significantly elevated the expression of adipokines, such as leptin, visfatin and resistin, compared to the treatment with the serum from healthy donors, resembling to what was observed in vivo in patients (Fig. $4 \mathrm{~g}, \mathrm{~h}$ ).

\section{Discussion}

As a long lasting chronic inflammatory disease, concern has been raised regarding the risk of premature 


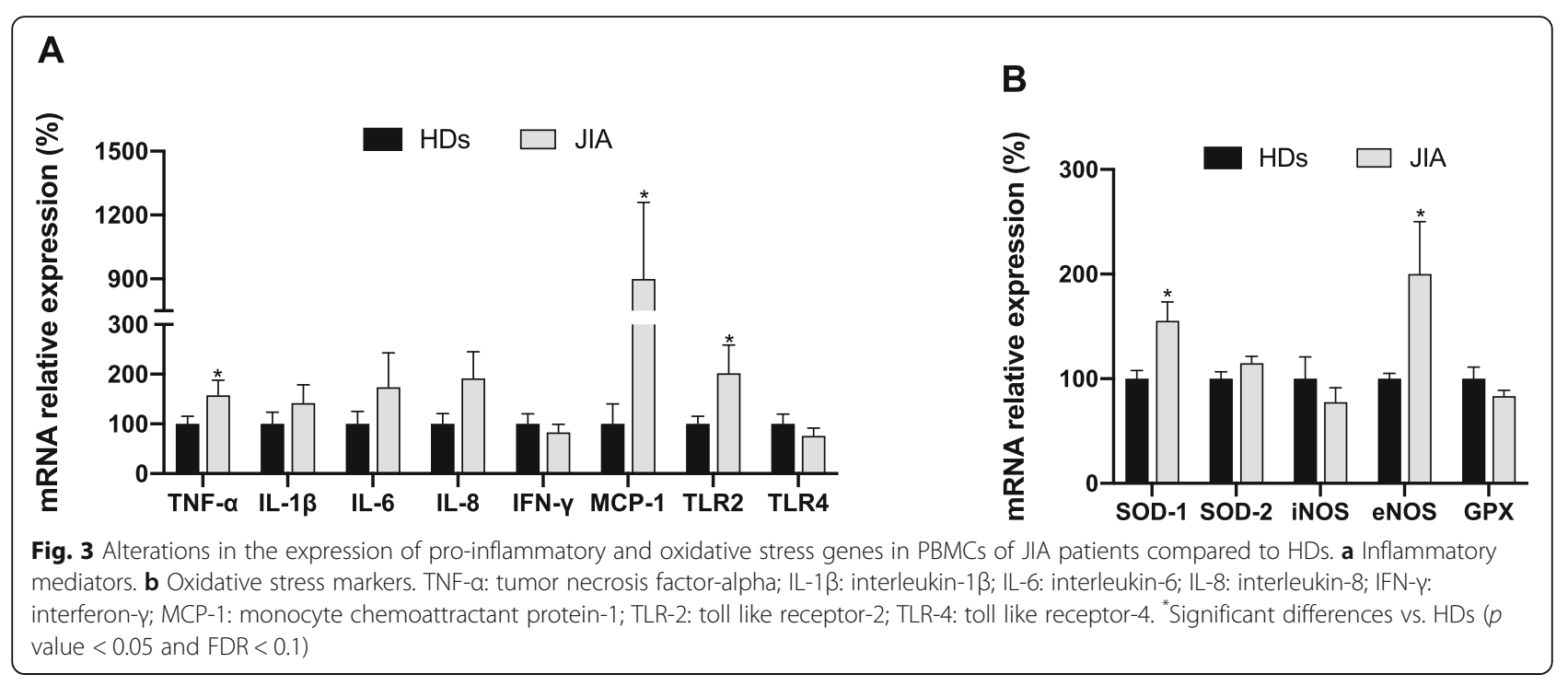

development of CVD in JIA. Several studies have been carried out to evaluate the CVD risk related to this pathology, most of them performed in children and adolescents, not considering a long remission state. This study describes for the first time that young adult JIA patients in clinical remission with or without treatment does not show increased traditional CVD risk factors nor early atherosclerosis, however do display subclinical signs of enhanced CVD risk, including high levels of inflammatory cytokines, adipokines, oxidative stress and endothelial activation markers, molecules with a relevant role in the onset and progression of endothelial dysfunction and atherosclerosis.

Obesity, MetSyn and smoking are recognized risk factors for CVD. Evidence regarding obesity rates in JIA is conflicting. Several studies described low BMI in patients with JIA, while others reported no differences with the general population or even increased BMI score in patients with JIA (reviewed in Coulson et al., 2013) [5]. In our cohort of adults JIA patients in remission, BMI was similar in JIA patients and HDs, which means that further studies on the effect of long-term disease and activity in BMI in patients should be carried out. On the other hand, there are few studies evaluating the prevalence of MetSyn or its hallmark, insulin resistance, in adults with JIA, and more specifically being under remission state. In our cohort of JIA patients with a duration of the disease of $13.47 \pm 5.47$ years, there were similar rates of MetSyn and insulin resistance between patients and age and sex-matched healthy donors. A recent study has evaluated the risk of MetSyn in adults with a history of juvenile arthritis, finding increased rates of MetSyn in this population compared to a non-arthritis cohort [30].

There are few studies reporting smoking rates in adolescents or adults with JIA. So far, published data reported same or even less smoking habit in young people with JIA [5]. To our knowledge this is the first study that reports rates of tobacco use in JIA adults, and similarly to what those studies found, no differences in the smoking habit were observed in our cohort of JIA adults.

A number of publications have informed some data about lipid profile in children with JIA, although the results are controversial. Several authors reported decreased levels of HDL and higher levels of triglycerides in children with JIA, although these observations were more associated with high disease activity (reviewed in [5]). Our data shows that adults JIA patients had significantly increased levels of TC even though they were on a remission state, suggesting that long duration disease could affect lipid profile regardless the disease activity.

In addition, early atherosclerosis has been studied in JIA [31]. Results are conflicting since several crosssectional studies described greater CIMT in patients with oligo- and polyarticular JIA [32, 33], while others pointed out to similar CIMT between patients and controls [34]. None of these studies took into account patients in remission. In our cohort of adult JIA patients, a trend to increased CIMT was observed with no significant differences, which might suggest that abnormalities in CIMT could be likely given to a longer active disease duration.

Of note, in our cohort of JIA patients elevated serum levels of inflammatory cytokines including TNF- $\alpha$, IL- 6 and IL- $1 \beta$ are evidenced. Pro-inflammatory cytokines are known to induce the differentiation and activation of inflammatory cells, the activation of osteoclasts and general inflammation at the joint level. In this context, it is not surprising that previous studies reported levels of these pro-inflammatory cytokines related to the disease 


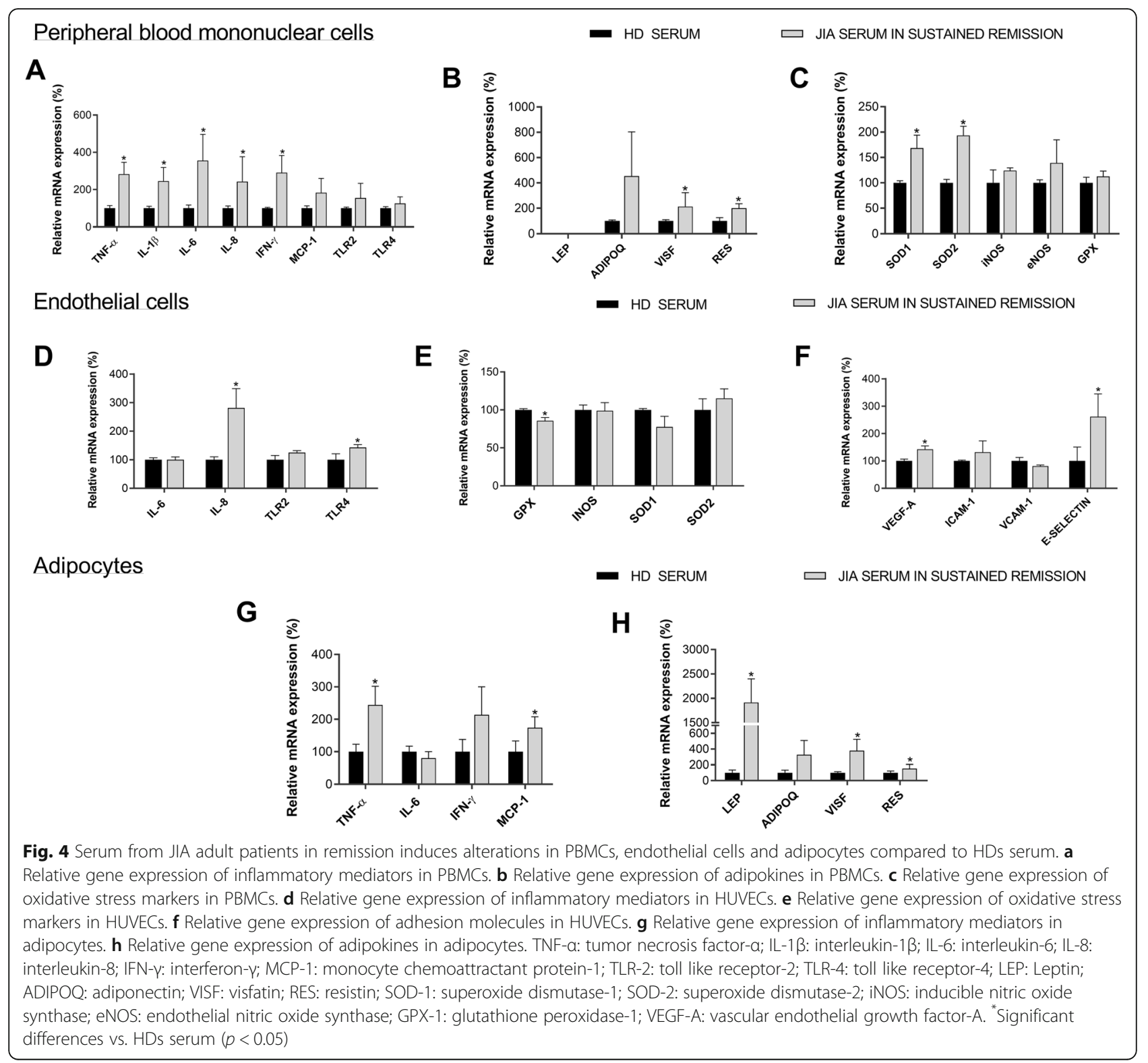

activity and the response to determined treatments [35]. That makes this finding relevant since in our cohort of JIA patients serum levels of inflammatory cytokines were significantly elevated compared to HDs despite being in clinical remission state. Besides, mRNA expression of inflammatory molecules was elevated in leukocytes purified from those JIA patients. Focusing on persistent inflammation as a driver for the development of CVD risk, these cytokines (IL-1 $\beta$, IL- 6 and TNF- $\alpha$ have been implicated in the development of atherosclerosis in rheumatoid arthritis [36], suggesting that in JIA adults under remission phase still could persist subclinical markers of CVD risk which should be monitored.

In addition, the high levels of pro-inflammatory molecules observed in active JIA were associated with endothelial activation [37]. In this sense, serum levels of VEGF-A were also significantly elevated in our cohort of JIA patients in clinical remission, alongside an increase in the mRNA expression of molecules involved in oxidative stress and endothelial activation of JIA PBMCs, suggesting an alteration in the endothelium. Data that was confirmed with the fact that the treatment of healthy PBMCs and endothelial cells with serum from those JIA patients induced the expression of inflammatory, oxidative stress and endothelial activation molecules, indicating that molecules present in the serum of those patients could activate the vascular system even though they were in clinical remission.

On the other hand, adipose tissue has recently been recognized as a complex and dynamic endocrine organ 
with an intricate role in homeostasis of the whole body $[38,39]$. Thus, adipokines are involved in not only in lipid and glucose metabolism, but also cardiovascular homeostasis and inflammatory and immune functions among other physiological functions. In consequence, adipokines such as leptin, resistin and adiponectin are considered key players in the regulation of inflammation [40-42]. In the present work, serum levels of adipokines were altered in JIA patients, showed by a significant increase in the serum levels of resistin and visfatin. In addition, in vitro treatment of PBMCs and adipocytes with serum from JIA patients in sustained remission induced the mRNA expression of inflammatory molecules and these adipocytokines. Similar to what others group have found, in our hands levels of leptin were not different between JIA patients and controls [43, 44]. In addition, in refractory JIA children, no alteration in adiponectin levels was found, which also is in line with our data [45]. On the other hand, resistin levels has already been shown elevated in children with JIA compared to the control group, regardless BMI and were dependent on the disease activity [46]. However, no study has evaluated the levels of resistin in adults JIA patients. Contrary to what those authors reported, our study revealed high levels of resistin in remission state. Moreover, high levels of visfatin has been described in JIA and shown to be a potential biomarker of Methotrexate response in JIA children [47]. Both adipokines, visfatin and resistin have an established proinflammatory role, the fact that these molecules were elevated in our cohort of JIA patients supports the concept that subclinical inflammation might exist in JIA under a long time of remission.

These results might indicate that the longstanding inflammation, even under remission conditions, might promote alterations in the adipose tissue of these patients, contributing to a subclinical cardiovascular risk in these patients.

The major limitation of this study lies in the limited number of patients involved. The small $\mathrm{n}$ size did not allow us to stratify patients according to JIA subtypes, presence of CVD risk factors or different treatments received. Meanwhile changes in parameters such as the increase in the CIMT in JIA can be significant in studies including a larger number of patients, we did not find any significant differences among JIA patients and HDs in our study. This fact might be due to the remission state or the number of patients included instead. Studies with larger sample size should be carried out to strengthen our conclusions. The study design (cross-sectional) could be another limitation, since we are not able to detect changes in the clinical and subclinical cardiovascular risk signs possible occurred in the remission state compared to the active phase in the same patient.

\section{Conclusions}

Long-term JIA adult patients in remission might have subclinical signs of inflammation and CVD risk, showed by an increase in the levels of inflammatory cytokines, endothelial activation and oxidative stress markers and adipokines, molecules closely involved in the alteration of the vascular system.

\section{Abbreviations \\ JIA: Juvenile Idiopathic Arthritis; CVD: Cardiovascular Disease; RA: Rheumatoid arthritis; CIMT: Carotid intima media thickness; IL-1: Interleukin 1; IL- 6: Interleukin 6; TNF-a: Tumor necrosis factor alpha; ICAM: Intercellular adhesion molecule; ILAR: International League of Associations for Rheumatology; JADAS: Juvenile Arthritis Disease Activity Score; CRP: C reactive protein; ACPAs: Anti-citrullinated protein antibodies; RF: Rheumatoid factor; Hb1Ac: Hemoglobin 1Ac; TC: Total cholesterol; HDL: High density lipoprotein; Triglycerides (TGs); ApoA: Apolipoprotein A; ApoB: Apolipoprotein B; ESR: Erythrocyte sedimentation rate; BMI: Body Mass Index; T2DM: Type 2 Diabetes Mellitus; MetSyn: Metabolic Syndrome; HOMA- IR: Homeostatic Model Assessment-Insulin Resistance; AdipoQ: Adiponectin; PBMCs: Peripheral Blood Mononuclear Cells; HUVECs: Human Umbilical Vein

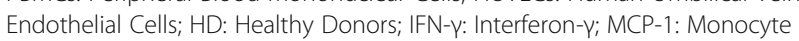 chemoattractant protein 1; TLR2: Toll Like Receptor 2; TLR4: Toll Like Receptor 4; SOD-1: Superoxide Dismutase 1; SOD-2: Superoxide Dismutase 2; iNOS: inducible Nitric Oxide Synthase; eNOS: endothelial Nitric Oxide Synthase; GPX-1: Glutathione Peroxidase-1; VEGF-A: Vascular Endothelial Growth Factor A; VCAM: Vascular Cell Adhesion Molecule; RT-PCR: Reverse Transcription Polymerase Chain Reaction; GAPDH: glyceraldehyde-3- phosphate dehydrogenase; HPRT: hypoxanthine-guanine phosphoribosyltransferase}

\section{Acknowledgments}

The authors would like to thank all the patients who participated in the study.

\section{Authors' contributions}

ICAV and RRM provided medical care of the patients. ICAV, IAR and NB drafted the initial manuscript, confirmed revisions, and approved the final manuscript as submitted. MCAG and IAR performed in vivo and in vitro experiments. AE, CLP and EC reviewed and revised the manuscript and approved the final manuscript as submitted. RGR and MMM reviewed the manuscript. All authors approved the final manuscript as submitted and agree to be accountable for all aspects of the work.

\section{Funding}

This work was supported by a grant from the Spanish Society of Pediatric Rheumatology (Moving4 grant, call 2018) and Rheumatic Diseases Network (RIER), Instituto de Salud Carlos III (RD16/0012/0015). C.L-P was supported by a contract from the Spanish Junta de Andalucía ("Nicolas Monardes" program)

\section{Availability of data and materials}

The datasets used and/or analyzed during the current study are available from the corresponding author on reasonable request.

\section{Ethics approval and consent to participate}

The current study was approved by the Institutional Review Board at Reina Sofia Hospital. Original data collection and consenting procedures were approved by the ethical committee of Reina Sofia Hospital.

Consent for publication

Written consent was obtained from all the participants in the study for publication.

Competing interests

The authors declare that they have no competing interests. 


\section{Author details}

'Rheumatology Department, IMIBIC/Reina Sofía University Hospital/University of Cordoba, Cordoba, Spain. ${ }^{2}$ Medicine Department, University of Cordoba/ IMIBIC/Reina Sofía University Hospital, Cordoba, Spain. ${ }^{3}$ Department of Cell Biology, Physiology and Immunology, IMIBIC, Reina Sofía University Hospital, University of Córdoba, Cordoba, Spain. ${ }^{4}$ CIBER Fisiopatología de la Obesidad y Nutrición (CIBEROBN), Instituto de Salud Carlos III, Madrid, Spain.

Received: 13 January 2020 Accepted: 3 July 2020

Published online: 14 July 2020

\section{References}

1. Bertilsson L, Andersson-Gare B, Fasth A, Petersson IF, Forsblad-D'elia H. Disease course, outcome, and predictors of outcome in a population-based juvenile chronic arthritis cohort followed for 17 years. J Rheumatol. 2013;40: 715-24.

2. Selvaag AM, Aulie HA, Lilleby V, Flato B. Disease progression into adulthood and predictors of long-term active disease in juvenile idiopathic arthritis. Ann Rheum Dis. 2016;75:190-5.

3. Woo P. Cytokines and juvenile idiopathic arthritis. Curr Rheumatol Rep. 2002;4(6):452-7

4. England BR, Thiele GM, Anderson DR, Mikuls TR. Increased cardiovascular risk in rheumatoid arthritis: mechanisms and implications. BMJ. 2018;23(361): k1036.

5. Coulson EJ, Ng W-F, Goff L, Foster HE. Cardiovascular risk in juveline idiopathic arthritis. Rheumatology. 2013:52(7):1163-71.

6. Lorenz MW, Markus HS, Bots ML, Rosvall M, Sitzer M. Prediction of clinical cardiovascular events with carotid intima-media thickness: a systematic review and meta-analysis. Circulation. 2007;115(4):459-67.

7. Tyrrell PN, Beyene J, Feldman BM, McCrindle BW, Silverman ED, Bradley TJ. Rheumatic disease and carotid intima-media thickness: a systematic review and meta-analysis. Arteriosc Thromb Vasc Biol. 2010;30(5):1014-26.

8. van Sijl AM, Peters MJ, Knol DK, de Vet HC, Gonzalez-Gay MA, Smulders YM, et al. Carotid intima media thickness in rheumatoid arthritis as compared to control subjects: a meta-analysis. Semin Arthritis Rheumatism. 2011;40(5): 389-97.

9. Gonzalez-Juanatey C, Llorca J, Martin J, Gonzalez-Gay MA. Carotid intimamedia thickness predicts the development of cardiovascular events in patients with rheumatoid arthritis. Semin Arthritis Rheumatism. 2009;38(5): 366-71

10. Sattar N, McCarey DW, Capell H, Mclnnes IB. Explaining how "high-grade" systemic inflammation accelerates vascular risk in rheumatoid arthritis. Circulation. 2003;108:2957-63.

11. Brunner H, Cockcroft JR, Deanfield J, Donald A, Ferrannini E, Halcox J, et al. Working group on Endothelins and endothelial factors of the European Society of Hypertension. Endothelial function and dysfunction. Part II: association with cardiovascular risk factors and diseases. A statement by the working group on Endothelins and endothelial factors of the European Society of Hypertension. J Hypertens. 2005;23:233-46.

12. Ramonda $R$, Lo Nigro A, Modesti $V$, Nalotto $L$, Musacchio $E$, laccarino $L$, et al. Atherosclerosis in psoriatic arthritis. Autoimmun Rev. 2011;10:773-8.

13. Vlahos AP, Theocharis P, Bechlioulis A, Naka KK, Vakalis K, Papamichael ND, et al. Changes in vascular function and structure in juvenile idiopathic arthritis. Arthritis Care Res. 2011;63:1736-44.

14. Breda L, Di Marzio D, Giannini C, Gaspari S, Nozzi M, Scarinci A, et al. Relationship between inflammatory markers, oxidant-antioxidant status and intima-media thickness in prepubertal children with juvenile idiopathic arthritis. Clin Res Cardiol. 2013;102:63-71.

15. Ilisson J, Zagura M, Zilmer K, Salum E, Heilman K, Piir A, et al. Increased carotid artery intima-media thickness and myeloperoxidase level in children with newly diagnosed juvenile idiopathic arthritis. Arthritis Res Ther. 2015; 17:180.

16. Del Guidice E, Dilillo A, Tromba L, La Torre G, Blasi S, Conti F, et al. Aortic, carotid intima-media thickness and flow-mediated dilation as markers of early atherosclerosis in a cohort of pediatric patients with rheumatic diseases. Clin Rheumatol. 2018:37(6):1675-82.

17. Dolezalová P, Telekesová P, Nemcová D, Hoza J. Soluble adhesion molecules ICAM-1 and E-selectin in juveline arthritis: clinical and laboratory correlations. Clin Exp Rheumatol. 2002;20(2):249-54.

18. Markula-Patjas KP, Ivaska KK, Pekkinen M, Andersson S, Moilanen E, Viljakainen HT, et al. High adiposity and serum leptin accompanied by altered bone turnover markers in severe juveline idiopathic arthritis. J Rheumatol. 2014:41(12):2474-81.

19. Petty RE, Southwood TR, Manners P, Baum J, Glass DN, Goldenberg J, et al. International League of Associations for Rheumatology. International League of Associations for Rheumatology classification of juvenile idiopathic arthritis: second revision, Edmonton, 2001. J Rheumatol. 2004:31(2):390-2.

20. Nordal EB, Zak M, Aalto K, Berntson L, Fasth A, Herlin T, et al. Validity and predictive ability of the juvenile arthritis disease activity score based on CRP versus ESR in a Nordic population-based setting. Ann Rheum Dis. 2012;71: 1122-7.

21. Consolaro A, Negro G, Chiara Gallo M, Braccionali G, Ferrari C, Schiappapietra B, et al. Defining criteria for disease activity states in nosystemic juveline idiopathic arthritis based on a three-variable juveline arthritis disease activity score. Arthritis Care Res. 2014;66(11):1703-9.

22. Wallace CA, Ruperto N, Giannini E. Childhood arthritis and rheumatology research Alliance., pediatric rheumatology international trials organization. pediatric rheumatology collaborative study group. Preliminary criteria for clinical remission for select categories of juvenile idiopathic arthritis. J Rheumatol. 2004;31(11):2290-4.

23. Millan J, Pintó X, Muñoz A, Zúñiga M, Rubies-Prat J, Pallardo LF, et al. Lipoprotein ratios: physiological significance and clinical usefulness in cardiovascular prevention. Vasc Health Risk Manag. 2009;5:757-65.

24. Lima LM, Md C, Sousa MO. Apo B/apo A-I ratio and cardiovascular risk prediction. Arq Bras Cardiol. 2007;88(6):e187-90.

25. Walldius $\mathrm{G}$, Jungner I. The apoB/apoA-I ratio: a strong, new risk factor for cardiovascular disease and a target for lipid-lowering therapy--a review of the evidence. J Intern Med. 2006;259(5):493-519.

26. Agca R, Heslinga SC, Rollefstad S, Heslinga M, McInnes IB, Peters MJL, et al. EULAR Recommendations for Cardiovascular Disease Risk Management in Patients With Rheumatoid Arthritis and Other Forms of Inflammatory Joint Disorders: 2015/2016 Update. Ann Rheum Dis. 2017;76(1):17-28.

27. Matthews DR, Hosker JP, Rudenski AS, Naylor BA, Treacher DF, Turner RC. Homeostasis model assessment: insulin resistance and beta-cell function from fasting plasma glucose and insulin concentrations in man. Diabetologia. 1985;28:412-9.

28. Guzman-Ruiz R, Ortega F, Rodríguez A, Vazquez-Martinez R, Diaz-Ruiz A, Garcia-Navarro S, et al. Alarmin high-mobility group B1 (HMGB1) is regulated in human adipocytes in insulin resistance and influences insulin secretion in $\beta$-cells. Int J Obes (Lond). 2014;38:1545-54.

29. Pfaffl MW, Tichopad A, Prgomet C, Neuvians TP. Determination of stable housekeeping genes, differentially regulated target genes and sample integrity: BestKeeper - excel-based tool using pair-wise correlations. Biotechnol Lett. 2004:26:509-15.

30. Sule S, Fontaine K. Metabolic syndrome in adults with a history of juveline arthritis. Open Access Rheumatol. 2018;10:67-72

31. Bohr AH, Fuhlbridge RC, Pedersen FK, Ferranti SD, Muller K. Premature subclinical atherosclerosis in children and young adults with juveline idiopathic arthritis. A review considering preventive measures. Pediatric Rheumatol. 2016;14:3.

32. Breda L, Di Marzio D, Giannini C, Gaspari S, Nozzi M, Scarinci A, et al. Relationship between inflammatory markers, oxidant-antioxidant status and intima-media thickness in prepubertal children with juveline idiopathic arthritis. Clin Res Cardiol. 2013:102(1):63-71.

33. Pietrewicz E, Urban M. Early atherosclerosis changes in children with juveline idiopathic arthritis. Pol Merkur Lekarski. 2007:22:211-4.

34. Mani P, Uno K, Duong M, Wolski K, Spalding S, Husni ME, et al. HDL function and subclinical atherosclerosis in javelin idiopathic arthritis. Cardiovas Diagn Ther. 2016;6(1):34-43.

35. Kaminiarczyk-Pyzalka D, Adamczak K, Mikos H, Klimecka I, Moczko J, Niedziela M. Proinflammatory cytokines in monitoring the course of disease and effectiveness of treatment with Etanercept (ETN) of children with Oligo- and Polyarticular juvenile idiopathic arthritis (JIA) Clin Lab. 2014;60(9):1481-90.

36. Libby P. Role of inflammation in atherosclerosis associated with rheumatoid arthritis. Am J Med. 2008;221(10):21-31.

37. De Benedetti $F$, Vivarelli M, Pignatti $P$, Oliveri $M$, Massa M, Pistorio $A$, et al. Circulating levels of soluble E-selectin, P-selectin and intercellular adhesion molecule-1 in patients with juveline idiopathic arthritis. J Rheumatol. 2000; 27:2246-50

38. Galic S, Oakhill JS, Steinberg GR, Ram R. Adipose tissue as an endocrine organ. Mol Cell Endocrinol. 2010;316:129-39 17. 
39. Scherer PE. Adipose tissue: from lipid storage compartment to endocrine organ. Diabetes. 2006;55:1537-15459.

40. Friedman J. The long road to leptin. J Clin Invest. 2016;126:4727-34.

41. Shuldiner AR, Yang R, Gong DW. Resistin, obesity, and insulin resistance-the emerging role of the adipocyte as an endocrine organ. N Engl J Med. 2001; 345:1345-6.

42. Yamauchi T, Kamon J, Waki H, Terauchi Y, Kubota N, Hara K, et al. The fatderived hormone adiponectin reverses insulin resistance associated with both lipoatrophy and obesity. Nat Med. 2001;7:941-6.

43. Maciejewska-Paszek I, Grochowska-Niedworok E, Siwiec A, Gruenpeter A, Du $L$, Irzyniec $T$. Influence of etanercept on leptin and ghrelin secretion in children with juvenile idiopathic arthritis. J Int Med Res. 2017;45(2):525-32.

44. Markula-Patjas K, Valta H, Pekkinen M, Andersson S, Aalto K, Lahdenne $P$, et al. Body composition and adipokines in patients with juvenile idiopathic arthritis and systemic glucocorticoids. Clin Exp Rheumatol. 2015;33(6):924-30

45. Markula-Patjas KP, Ivaska KK, Pekkinen M, Andersson S, Moilanen E, Viljakainen HT, et al. High adiposity and serum leptin accompanied by altered bone turnover markers in severe juvenile idiopathic arthritis. J Rheumatol. 2014;41(12):2474-81.

46. Gheita TA, El-Gazzar II, El Shazly RI, El-Din AM, Abdel-Rasheed E, Bassyouni $\mathrm{RH}$. Elevated serum resistin in juvenile idiopathic arthritis: relation to categories and disease activity. J Clin Immunol. 2013;33(1):297-301.

47. Funk RS, Singh R, Pramann L, Gigliotti N, Islam S, Heruth DP, et al. Nicotinamide phosphoribosyltransferase attenuates methotrexate response in juvenile idiopathic arthritis and in vitro. Clin Transl Sci. 2016;9(3):149-57.

\section{Publisher's Note}

Springer Nature remains neutral with regard to jurisdictional claims in published maps and institutional affiliations.

Ready to submit your research? Choose BMC and benefit from:

- fast, convenient online submission

- thorough peer review by experienced researchers in your field

- rapid publication on acceptance

- support for research data, including large and complex data types

- gold Open Access which fosters wider collaboration and increased citations

- maximum visibility for your research: over $100 \mathrm{M}$ website views per year

At $\mathrm{BMC}$, research is always in progress.

Learn more biomedcentral.com/submissions 